\title{
Animal Models of Preeclampsia
}

\author{
Eduardo Podjarny, Gyorgy Losonczy, and Chris Baylis \\ Department of Nephrology and Hypertension, Meir Hospital, Sackler Faculty of Medicine, Tel-Aviv \\ University, Israel; Department of Pulmonology, Semmelweis University, Budapest, Hungary; and \\ the Department of Physiology, West Virginia University, Morgantown, WV
}

\section{Abstract}

There have been many attempts to produce animal models that mimic the hypertensive disorders of pregnancy, especially preeclampsia, but most are incomplete when compared to the full spectrum of the human disease. This review assesses a number of these models, organized according to the investigators attempt to focus on a specific pathogenic mechanism believed to play a role in the human disease. These mechanisms include uterine ischemia, impairments in the nitric oxide system, insulin resistance, overactivity of the autonomic nervous and/or renin-angiotensin systems, activation of a systemic inflammatory response, and most recently, activation of circulating proteins that interfere with angiogenesis. In addition a model of renal disease that mimics superimposed preeclampsia is discussed. Defining these animal models should help in our quest to understand the cause, as well as to test preventative and therapeutic strategies in the management of these hypertensive disorders of pregnancy.

\section{Keywords}

hypertension; proteinuria; glomerular endotheliosis; intrauterine growth retardation

Preeclampsia, the most frequent, serious, hypertensive complication of pregnancy, occurs spontaneously only in women and higher apes. ${ }^{1}$ The disorder is caused by pregnancy and cured by delivery and has an overall incidence of $5 \%$ to $7 \%,{ }^{2}$ although risk factors such as multiple pregnancy, extremes of maternal age, family history, essential hypertension, and renal disease increase its occurrence. The maternal symptoms of preeclampsia result from suppression of the normal physiologic responses to pregnancy and include generalized vasoconstriction; increased responsiveness to vasoconstrictors, increased blood pressure (BP), increased capillary permeability, sudden severe edema, decreases in plasma volume, increased intravascular coagulation, reductions in organ perfusion, decreases in glomerular filtration rate (GFR), proteinuria, widespread vascular endothelial damage including glomerular endotheliosis and intrauterine growth restriction (IUGR). ${ }^{2}$ The primary defect is thought to originate at the maternal-fetal interface in association with reduced placental perfusion, leading to fetoplacental ischemia. Placental (but not fetal) tissue is required because preeclampsia occurs in women with hyaditiform mole. ${ }^{3}$ It is believed that the ischemic placenta produces a circulating agent that causes widespread dysfunction of the maternal vascular endothelium, ${ }^{4}$ leading to the various systemic manifestations of preeclampsia. Thus, an ideal animal model to study pathogenesis, prevention, and treatment should incorporate as much of the earlierdescribed factors as possible.

Address reprint requests to Chris Baylis, Director, UF Hypertension Center, University of Florida, POB 100274, Gainesville, FL, 32610-0274. Tel: (353) 392-7869; Fax: (352) 392-7935. baylisc@ufl.edu. 
There have been numerous attempts to generate animal models of preeclampsia, many of which have been unsuccessful. For example, although essential hypertension is a risk factor for development of preeclampsia in women, pregnancy is powerfully antihypertensive when superimposed on a variety of models of established hypertension in rats, whether genetic or experimentally induced. ${ }^{5-7}$ In rats with various forms of underlying renal disease, pregnancy often improves renal function ${ }^{8}$ and only in one situation (passive Heymann nephritis; a model of membranous glomerulonephritis) is renal function acutely worsened by the pregnancy. ${ }^{9}$

Below, we discuss the more promising animal models of preeclampsia that are currently in use and evaluate their strengths and weaknesses.

\section{The Uteroplacental Ischemia Model of Preeclampsia}

This model is based on the primary defect believed to trigger preeclampsia in women. During normal human pregnancy, blood flow to the uterus increases, up to approximately $25 \%$ of the cardiac output by late pregnancy. ${ }^{10}$ Dilation of the spiral arteries during the first trimester reduces uteroplacental vascular resistance and increases uteroplacental blood flow. ${ }^{11}$ In women destined to develop preeclampsia, uteroplacental blood flow is reduced by $50 \%$ to $70 \%$. 12

In 1939, Ogden et al ${ }^{13}$ tested the hypothesis, first suggested by Young ${ }^{14}$ in 1914 , that uteroplacental ischemia can induce hypertension in pregnant animals. They clamped the abdominal aorta of anesthetized dogs to induce acute reductions of approximately $50 \%$ in uteroplacental perfusion pressure. The BP increased by approximately $25 \mathrm{~mm} \mathrm{Hg}$ in pregnant dogs within minutes and returned to baseline on release of the clamp, without changing in nonpregnant dogs. Adaptations of this technique subsequently have been used by others. ${ }^{13}$, 15,16 Woods and Brooks ${ }^{15}$ used conscious pregnant dogs and showed that when abdominal aortic pressure was reduced by approximately $40 \%$, systemic BP rapidly increased and remained high until aortic occlusion was stopped, when BP returned to baseline levels. These effects were independent of angiotensin II whereas cyclooxygenase inhibition and thromboxane $\mathrm{A} 2 /$ prostaglandin $\mathrm{H} 2$ receptor blockade prevented the pressor response to reductions in uteroplacental perfusion pressure. ${ }^{16}$ Later studies in pregnant rabbits ${ }^{17-19}$ and rats, ${ }^{20}$ showed that agonists of the thromboxane $\mathrm{A} 2 /$ prostaglandin $\mathrm{H} 2$ receptors are more potent hypertensive substances than in nonpregnant controls, a finding that, together with that of Woods ${ }^{16}$ supports a role for thromboxane A2 as a potential mediator of preeclamptic hypertension. Abitol et al also observed marked increases of BP in conscious dogs in response to chronic uteroplacental ischemia, ${ }^{21}$ although BP was very variable in controls. Proteinuria was seen in 50\% of the animals and endothelial cell swelling and subendothelial electron-dense deposits were present, as were placental infarcts.

A number of researchers have investigated the impact of chronic reductions in uteroplacental perfusion pressure during pregnancy in a variety of other species. In the pregnant rabbit, aortic clamping increased BP within 24 hours and fetal compromise, proteinuria, glomerular endotheliosis, and intracapillary fibrinoid deposition were seen. ${ }^{22}$ In conscious rabbits, ${ }^{23,24}$ substantial increases in BP were seen at 1 and 7 days after aortic constriction, as well as increased $\alpha$-adrenergic tone, decreased plasma angiotensin II concentration with no change in plasma prostanoids. Platelet count decreased suggesting activation/consumption of platelets and mesangial fibrin deposition, proteinuria, placental necrosis, and IUGR also were seen. This hypertension was independent of the rennin-angiotensin system.

Aortic constriction in the rat leads to hypertension and proteinuria in pregnancy. ${ }^{25}$ This model was adapted by Alexander et al, ${ }^{26}$ who used constriction of the lower abdominal aorta as well as both ovarian arteries (to prevent a compensatory increase in placental blood flow) and these investigators also observed hypertension, proteinuria, and decrements in renal function in 
pregnant but not virgin rats. In addition, endothelial dysfunction and IUGR were seen as well as increased renal expression of preproendothelin and increased thromboxane. Again, this model of hypertension was independent of the renin-angiotensin system. ${ }^{26-29}$

In contrast, in the conscious pregnant sheep, stepwise reductions in uterine blood flow, down to approximately $20 \%$ of normal, had no effect on BP although fetal hypoxia developed. ${ }^{30}$ Leffler et $\mathrm{al}^{31}$ also reported no change in BP in the conscious pregnant sheep when uteroplacental perfusion pressure was markedly reduced and pregnancy ended in abortion. In contrast, when pregnant ewes were fed a high salt diet $(\sim 8 \times$ normal intake), BP increased slowly and substantially and some hypertensive pregnant ewes developed convulsions while all had reduced urine volume and exhibited respiratory distress caused by pulmonary edema. Salt loading or reductions in uteroplacental perfusion pressure alone caused no adverse effects in either pregnant or nonpregnant sheep..$^{31}$

Studies in the rhesus monkey ${ }^{32}$ suggested that BP increased after reductions in uteroplacental perfusion pressure although only one sham-operated control was studied. Combs et $\mathrm{al}^{33}$ and

Zhou et $\mathrm{al}^{34}$ made longitudinal measurements of BP in the conscious, chronically instrumented rhesus monkey, for 4 weeks after reduction of the uterine perfusion pressure in late pregnancy. Most of the pregnant monkeys became hypertensive. However, Zhou et $\mathrm{al}^{34}$ also reported an increased depth of decidual, vascular, and myometrial trophoblast invasion, which contrasts to women with preeclampsia in whom uteroplacental ischemia is associated with shallow trophoblast invasion resulting in the failed dilation of the spiral arteries. ${ }^{35}$ In pregnant primates (Papio anubis), approximately 60\% reduction of aortic flow on day 100 of the 160 days of pregnancy resulted in an approximately $30 \%$ increase in BP at term (measured under anesthesia), while renal vascular resistance also was increased. ${ }^{36}$ Furthermore, the pregnancyinduced expansion of the plasma volume was delayed, some monkeys developed proteinuria, and IUGR was seen, as well as an increased incidence of intrauterine fetal death. Plasma renin activity was reduced, similarly to human preeclampsia, and hyperuricemia also developed. ${ }^{36}$

An alternate method to reduce uterine blood flow is by occlusion and/or banding of the arteries supplying the uterus. ${ }^{37}$ In dogs, the maneuver resulted in a gradual increase in BP and proteinuria after the animals had become pregnant. ${ }^{38}$ Progressive and marked increases in BP occurred over the second and third trimester. Although this is an impressive longitudinal study, nonpregnant animals were not included as controls. Similarly banded rats and rabbits failed to develop any symptoms during pregnancy ${ }^{39}$ and in the rhesus monkey, no hypertension or proteinuria was observed, although fetal loss was increased after the banding of the uterine arteries. ${ }^{40}$ Cavanagh et al ${ }^{41,42}$ were successful in inducing the major symptoms of preeclampsia in baboons by using this technique.

Overall, it does appear that aortic constriction during pregnancy leads to hypertension in a variety of species. Whether this is entirely or partly caused by reductions in uteroplacental perfusion pressure is less clear because the more selective method of reducing uterine blood flow is much less reproducible as a model of hypertension in pregnancy. Aortic constriction per se may have different hemodynamic consequences (eg, on cardiac output, sympathetic nervous system, sympathetic nervous system, and so forth) in pregnant versus nonpregnant animals. Thus, clear experimental proof for uteroplacental ischemia being a long-term inducer of significant hypertension is still lacking. There is evidence from animal studies that reductions in uteroplacental perfusion pressure cause placental ischemia and necrosis with fetal growth retardation and intrauterine fetal death in several species. Furthermore, renal histologic changes reminiscent of preeclampsia can be induced by experimental reductions in uteroplacental perfusion pressure in some species. 


\section{Chronic Nitric Oxide Synthase Inhibition During Pregnancy}

Rather than attempting to reproduce the entire disease, an alternative approach is to examine the maternal manifestations of preeclampsia at the level of the endothelium. Interest has focused on nitric oxide (NO) given the evidence indicating that vascular tone is tonically controlled by shear regulated, locally produced, endothelial NO. Chronic nitric oxide synthase (NOS) inhibition produced dose-dependent sustained hypertension in nonpregnant animals, together with renal vasoconstriction, increased glomerular blood pressure, proteinuria, and glomerular injury. ${ }^{43}$ Whether NO plays a role in the gestational vasodilation is less certain. Most animal and clinical evidence argues against a role for $\mathrm{NO}$ as the exclusive peripheral vasodilator and the endothelial NOS (eNOS)knock-out mouse exhibited a decrease in BP during pregnancy, to the wild-type value, ${ }^{44}$ although others reported further increases of BP in pregnancy in the eNOS knock-out model. ${ }^{45}$

Nevertheless, unlike many other models of hypertension, in which pregnancy is antihypertensive, ${ }^{5-7}$ chronic NOS inhibition produced a dose-dependent hypertension in pregnant rats, maintained through to term (Fig. 1). The chronically NOS-inhibited pregnant rat also exhibited renal vasoconstriction leading to a decrease in GFR (Fig. 1), proteinuria, suppression of the normal volume expansion, and increased maternal and fetal morbidity and mortality ${ }^{46}$ in a pattern that resembled preeclampsia. Many subsequent studies confirmed our initial observations. ${ }^{47-52}$

There was also a report that fetal malformations and IUGR occur in the absence of maternal hypertension during chronic NOS inhibition in the rat. ${ }^{53}$ However, these investigators subsequently determined that the fetal malformations (limb reduction) were side effects of the NOS inhibitor used (L-NAME) and that although hypertension was not shown in the acutely prepared state, proteinuria and decreased GFR were consistent with hypertension in conscious, late in pregnancy, NOS-inhibited rats. ${ }^{54}$

Although increased NO may not be responsible for the entire peripheral vasodilation of normal pregnancy, it probably does play a role in some vascular beds, most notably the kidney. ${ }^{55} \mathrm{In}$ particular, studies from the laboratory of Conrad strongly suggested a primary role for NOmediated renal vasodilation that is signaled by the ovarian hormone relaxin and requires activation of the endothelin type B receptor. ${ }^{56,57}$ Our original studies reported that NO was necessary for the midterm renal vasodilation of pregnancy, ${ }^{46}$ although a recent publication by Danielson and Conrad ${ }^{58}$ suggested that vasodilatory prostaglandins can be recruited to compensate and maintain the midterm increase in GFR despite chronic NOS inhibition. This suggestion raised the issue of completeness of NOS inhibition and we recently repeated the studies of Danielson and Conrad ${ }^{58}$ but used a larger dose of NOS inhibitor, given for a longer duration, ${ }^{59}$ and found that the midterm increase in GFR was prevented completely and acute administration of the cyclooxygenase inhibitor indomethacin produced insignificant further renal vasoconstriction.

Thus, chronic NO deficiency in pregnancy led to certain manifestations resembling preeclampsia. Given that preeclamptic symptoms have been difficult to produce in the rat, this model has been useful in suggesting an important role for NO deficiency in preeclampsia. The usefulness of the model is somewhat limited, however, because this involves manipulation of an end point whose resemblance to preeclampsia may be fortuitous.

\section{Adriamycin Nephropathy Model}

A single dose of adriamycin given to the nonpregnant rat produces an experimental model of nephropathy with proteinuria, hypertension, and, eventually, chronic renal failure. ${ }^{60,61}$ 
Micropuncture studies showed that glomerular blood pressure remained normal, ${ }^{62}$ indicating that glomerular hypertension was not required for the development of glomerular injury.

Because underlying renal disease is a risk factor for preeclampsia ${ }^{2}$ we investigated the impact of superimposed pregnancy in a rat model of adriamycin nephropathy (AN), using a dose of adriamycin ( $3 \mathrm{mg} / \mathrm{kg}$, intravenously) that had minimal impact on BP, renal function, and renal histology in virgin females 5 weeks after administration. In contrast, term pregnant rats (also studied $\sim 5 \mathrm{wk}$ after induction of AN) developed hypertension, heavy proteinuria (Fig. 2), a relative decrease in GFR, and an augmented glomerular thromboxane B2/prostaglandin E2 ratio. ${ }^{63}$ Thus, pregnant rats with AN exhibited some of the manifestations of superimposed preeclampsia, ${ }^{63}$ although placental and renal histology was normal. The increased thromboxane B2/prostaglandin $\mathrm{E} 2$ ratio was reminiscent of findings in women with pregnancyinduced hypertension ${ }^{64}$ and was functionally important because treatment with the Tx receptor antagonist Daltroban from midpregnancy decreased BP in pregnant AN rats. ${ }^{65}$ These results suggested that adriamycin induced endothelial dysfunction; supported by our observation that pressor responsiveness to administered angiotensin II was restored in AN pregnant rats ${ }^{66}$ and that, in vitro, the mesenteric vascular reactivity of pregnant rats with AN showed an exaggerated response to noradrenaline ${ }^{67}$ It was possible to normalize BP by chronic treatment of pregnant AN rats with diltiazem (calcium channel blocker), methyldopa, or L-arginine and all these maneuvers also increased GFR. The proteinuria was diminished by diltiazem (which enhanced glomerular prostaglandin E2 synthesis) and by L-arginine, whereas methyldopa and daltroban had no effect. ${ }^{65,68}$ These findings suggested a specific role for derangements in intraglomerular vasodilator substances in the pathogenesis of the proteinuria.

Impaired NOS also was implicated in the hypertension because total NO production was reduced in late pregnancy in rats with $\mathrm{AN}^{69}$ and administration of L-arginine (Fig 2A), the NO synthase substrate, normalized BP in late pregnant rats with AN. ${ }^{70}$ Furthermore, acute NOS inhibition had no effect on BP in late pregnant $\mathrm{AN}$ rats whereas a pressor response was seen in normal pregnant or in AN virgin rats. ${ }^{69} \mathrm{~A}$ single dose of adriamycin (ADR) in non-pregnant rabbits caused a rapid deterioration of endothelium-dependent responses with endothelial generation of oxygen radicals via a flavoprotein containing oxido-reductase. ${ }^{71}$ Adriamycin was reduced at the reductase domain of the eNOS and thus was positioned to disrupt the balance between $\mathrm{NO}$ and superoxide production. A switch is likely to occur to superoxide, peroxynitrite, and hydrogen peroxide production; potent oxidants implicated in severe vascular pathologies $^{72}$ and decreased synthesis of NO. Whether these acute actions of ADR may affect eNOS bio-availability during pregnancy remains unknown.

The AN model resembles preeclampsia in women in that the maternal symptoms disappear soon after delivery, suggesting that all the systemic and renal derangements are functional in origin. ${ }^{73}$ However, the situation is different after 2 pregnancies. At the end of the second pregnancy, BP again was increased and proteinuria also was evident and these remained higher after 7 weeks compared with virgin AN rats (Fig 2B). Histologic examination of the kidneys in $\mathrm{AN}$ rats at the end of the second pregnancy and 5 weeks thereafter revealed a significant and irreversible worsening of the renal disease, characterized by a marked mesangial expansion..$^{72}$ In contrast, multiple pregnancies have no long-term deleterious effects on BP, renal function, or structure in normal rats, spontaneously hypertensive rats, or in rats with unilateral nephrectomy fed a high-protein diet $^{8}{ }^{8}$ and structure was unaffected by multiple pregnancy in rats with $5 / 6$ nephrectomy. ${ }^{74}$

In addition to its usefulness as a model resembling some features of preeclampsia, AN may serve to improve our understanding of mechanisms that lead to irreversible deterioration in renal function as a result of pregnancy. 


\section{Insulin Resistance/Chronic Hyperinsulinemia and Hypertension in Pregnancy}

Insulin resistance and hyperinsulinemia are characteristic of normal pregnancy and are maximal in the third trimester. Marked hyperinsulinemia has been described in women with preeclampsia and/or gestational hypertension ${ }^{75,76}$ although one group suggested that increased insulin resistance and hyperinsulinemia was confined to women with gestational hypertension, and not seen in preeclampsia. ${ }^{77}$ However, most investigators report a strong association between hyperinsulinemia and preeclampsia and even 2 months after delivery, preeclamptic women remain insulin resistant and hyperinsulinemic $;{ }^{76}$ a finding that may be related to the increased incidence of hypertension in women with a previous history of preeclampsia. ${ }^{78,79}$ The available clinical data also suggest that hyperinsulinemia, insulin resistance, and/or hyperglycemia in early or midpregnancy may be prognostic of later gestational hypertension and/or preeclampsia. ${ }^{80-83}$

The pathogenic role of insulin resistance/hyperinsulinemia has been evaluated in pregnant rats with chronic hyperinsulinemia induced with sustained-release insulin pellet subcutaneously. As shown in Figure 3, BP increased close to term and pregnant hyperinsulinemic rats also exhibited mildly reduced blood serum glucose levels, hypertriglyceridemia, and a reduced fractional excretion of sodium although urinary protein excretion remained unchanged. ${ }^{84,85}$ The normal increase in GFR (creatinine clearance) seen in pregnant rats was blunted in hyperinsulinemic pregnant rats. ${ }^{85,86}$ Total NO production was diminished and systolic BP correlated directly with serum insulin levels and inversely with total NO production. Treatment with $\mathrm{L}$-arginine normalized $\mathrm{BP}^{85,86}$ and increased total $\mathrm{NO}$ production and also increased the renal eNOS protein levels. This model also was associated with reduced fetal weight characterized by asymmetric growth retardation (Podjarny, unpublished observations). Treatment with L-arginine improved fetal weight without any change in the levels of serum insulin and glucose. ${ }^{85}$

The fructose-fed rat also develops insulin resistance and a slight increase in blood pressure. When the fructose-fed rat is pregnant, BP is significantly higher than in normal pregnant animals. ${ }^{87}$ These results suggest that fructose-induced diabetes could cause hypertension during pregnancy via the insulin-resistance-hyperinsulinemia-link.

\section{Angiogenesis Antagonism and Preeclampsia}

Vascular endothelial growth factor (VEGF) plays an important role in angiogenesis and defective angiogenesis may underlie defective placentation, leading to preeclampsia. Alternative splicing of the messenger RNA for one of the VEGF receptors (FLT1) produces a soluble form of FLT1 (sFLT1) that binds with, and antagonizes, both VEGF and placental growth factor (PIGF). Amniotic fluid levels and placental sFLT1 expression are increased in preeclamptic women and Maynard et al have reported that increased circulating levels of sFLT1 are seen in preeclamptic patients. ${ }^{88}$ Furthermore, these increased levels of sFLT1 lead to decreases in the plasma levels of free VEGF and PIGF, ${ }^{88}$ and these changes precede, and predict, both the occurrence and severity of preeclampsia ${ }^{89}$ and may be additive with other risk factors, such as insulin resistance. ${ }^{90}$

In addition to these clinical observations, Karumanchi's group have created a novel rat model of preeclampsia, produced by administration of sFLT1-expressing adeno-virus that causes high circulating levels of sFLT1. The adenovirus alone (control) had no effect in pregnant or virgin rats on BP or urinary protein excretion, and glomerular histology was normal (Fig. 4).

Administration of the sFLT1-expressing adenovirus (days 8-9 of gestation) produced a dosedependent hypertension, proteinuria, and glomerular endotheliosis in 16- to 17-day pregnant 
rats; which is impressive because the pregnant rat is refractory to many hypertensive interventions and rarely exhibits glomerular endotheliosis. The low-dose sFLT1 adenovirus produced levels of circulating sFLT1 seen in preeclamptic women. Further, sFLT1 also produced similar symptoms in nonpregnant rats (Fig. 4) and administered excess VEGF rescued the sFLT1-infused rat. ${ }^{88}$ In addition to their angiogenic actions, both VEGF and PIGF cause relaxation when superfused on precontracted rat renal arterioles in vitro, and this vasodilation was blocked by $\mathrm{sFLT} 1,{ }^{88}$ perhaps via inhibition of an NO-dependent pathway. Furthermore, although complete knockout of glomerular-specific VEGF is lethal, the heterozygous podocyte-specific VEGF mouse developed in the laboratories of Dr. Quaggin developed proteinuria and glomerular endotheliosis. ${ }^{91}$

This new model has been developed based on sound predictions from clinical observations. The fact that the hypertension, proteinuria, and glomerular endotheliosis are all reproduced by VEGF/PIGF antagonism suggest that the primary cause of the maternal manifestations of preeclampsia may be identified.

\section{Sympathetic Nervous System and Preeclampsia}

Stress has been implicated in an increased incidence of preeclampsia and IUGR in pregnant women ${ }^{92,93}$ and although the sympathetic output is increased moderately during normal pregnancy it is increased markedly in women with preeclampsia and reverts to normal after delivery. ${ }^{94,95}$

Studies in rats suggest that increased sympathetic nervous system activity may play a causal role in inducing a preeclampsia-like syndrome. Chronic stress induced by intermittent noise and overpopulation in the cage caused decreased weight gain, higher BP, endothelial dysfunction, mild proteinuria, and IUGR when compared with nonstressed pregnant animals. These changes were associated with an increased fetal adrenal weight (index of chronic stress). 96 Sympathetic hyperstimulation in pregnant rats (by stimulation of the celiac ganglion with bacterial lipopolysaccharide or potassium chloride) induced a hemolysis-elevated liver enzymes-low platelet-like syndrome associated with increased plasma catecholamines. ${ }^{97}$ Chronic, local, cold stimulation of paws also induced a preeclampsia-like syndrome in pregnant rats in association with increased levels of plasma norepinephrine compared with normal pregnant rats and nonpregnant rats. ${ }^{98} \mathrm{~A}$ decrease in trophoblast invasion, congestion, and fibrinoid deposits of the labyrinth also were found in the placenta of the cold, stressed, pregnant rats along with increased intrauterine fetal death and IUGR.

All of these models, which share clinical similarities with preeclampsia, may contribute to a better understanding of the interrelationship between increased sympathetic activity and endothelial and placental dysfunction in the pathogenesis of preeclampsia.

\section{Renin Angiotensin System and Preeclampsia}

There are striking modifications in the renin angiotensin system in normal pregnancy, with high levels of circulating prorenin, renin, angiotensinogen, and angiotensin II (ANGII), together with a marked blunting of the pressor actions of ANGII. In preeclamptic patients, the levels of prorenin, renin, angiotensinogen, and ANGII are all lower than in normal pregnancy and the vascular responsiveness to ANGII is restored. ${ }^{55}$ Some (but not all) groups have reported that certain polymorphisms in the angiotensinogen gene increase the risk for preeclampsia, ${ }^{55}$ and a recent study reported the presence of agonistic autoantibodies to ANGII in all women with preeclampsia. ${ }^{99}$

Overexpression of angiotensinogen led to higher baseline and pregnancy BP that was amplified in the presence of a double mutant, eNOS knock-out and angiotensinogen overexpression 
model (45). A transgenic mouse model was created with females expressing human angiotensinogen that developed hypertension, proteinuria, and glomerular enlargement only during pregnancy and only when mated with males expressing the human renin. ${ }^{100}$ A similar model was developed in the rat with similar results. ${ }^{101}$

Although these models are of interest, they may not be relevant to humans because in the rodents, the hypertension and other pathologies were associated with increased renin and angiotensin levels, whereas in preeclamptic women the various components of the renin angiotensin system are down-regulated versus normal pregnancy.

\section{Inflammatory Models}

Normal pregnancy has been characterized as an inflammatory state activated by placental debris, with preeclampsia representing an extreme. ${ }^{102}$ Inflammatory cytokines, produced by the placenta, are more abundant in preeclamptic than normal pregnancy. ${ }^{103}$ Markers of oxidative stress are increased in the placenta of women with preeclampsia and nitrotyrosine staining (a marker of peroxynitrite, a highly reactive toxic molecule), has been found in the preeclamptic placenta. ${ }^{104,105}$ In normal placenta, there is an adequate concentration of Larginine, which permits normal eNOS activity to form NO. In preeclampsia, a lower than normal L-arginine concentration is caused by arginase II overexpression. ${ }^{106}$ This, together with the high oxidant state induces eNOS uncoupling with increased generation of reactive oxygen species, more peroxynitrite synthesis, and further oxidative stress. ${ }^{107}$ In pregnant mice, there is a switch from anti-inflammatory to pro-inflammatory cytokines in response to lipopolysaccharide challenge. ${ }^{108}$ In the rat, injection of an ultra low dose of lipopolysaccharide caused increased BP, proteinuria, low platelet count, and glomerular thrombosis only in pregnancy. ${ }^{109}$ Furthermore, pregnant rats given lipopolysaccharide developed glomerular thrombosis secondary to NO substrate limitation, indicated by plasma arginine levels decreasing to near zero. In contrast, the same dose of lipopolysaccharide in nonpregnant rats produced only approximately 50\% decrements in plasma L-arginine, greater NO generation, and no glomerular thrombosis, thus pregnant females are particularly susceptible to development of L-arginine deficiency. ${ }^{110}$ Intermittent perfusion of the placenta, secondary to reduced trophoblast invasion (as seen in preeclampsia), may cause increased secretion of the inflammatory mediator tumor necrosis factor $\alpha$, and that may contribute to the activation of maternal endothelial cells that characterizes preeclampsia. ${ }^{111}$ In fact, direct administration of tumor necrosis factor $\alpha$ resulted in a preeclamptic-like response in rats in association with a reduction in NOS abundance ${ }^{112}$ as well as amplified vascular contraction and blunted NO vascular relaxation in isolated vessels. ${ }^{113}$ Circulating tumor necrosis factor $\alpha$ level are correlated tightly to measures of insulin resistance in pregnant women, ${ }^{114}$ suggesting that inflammation and worsening of insulin resistance may act synergistically in the derangements seen in preeclampsia.

\section{Other Models}

Starvation during late pregnancy produced a model of toxemia in the sheep and guinea pig with proteinuria, renal pathology, and placental ischemia; however, hypertension was not a common feature of this model. Because starvation does not cause preeclampsia in women, this model is probably of limited use. ${ }^{1}$ Calcium deficiency has been implicated as causal in essential hypertension and preeclampsia ${ }^{115,116}$ and dietary calcium restriction increased BP in the pregnant rat ${ }^{117}$ and the ewe, in the case of twin pregnancy. ${ }^{118}$ However, a recent multicenter National Institutes of Health study revealed no protective effect of calcium supplementation in the development of preeclamptic symptoms, ${ }^{119}$ which decreases enthusiasm for this model. 


\section{Summary}

A number of animal models have been identified that resemble some aspects of preeclampsia in normal women. Some of the maternal symptoms of preeclampsia can be produced by uterine ischemia although no quadriped spontaneously exhibits this disease. It may be that the combination of upright posture and uteroplacental ischemia are necessary for manifestation of the full syndrome. Chronic NOS inhibition in rats produces a pattern of change that resembles the symptoms of preeclampsia, and the preeclamptic-like response of rats with adriamycin nephropathy, and hyperinsulinemia is associated with endothelial dysfunction. The activation of stress responses and the sympathetic nervous system also results in some preeclamptic-like symptoms as does activation of endothelial inflammation. The VEGF antagonist model is also exciting and has reinforced the clinical data highlighting the importance of high free circulating levels of VEGF and PIGF in the maternal responses to pregnancy. In fact, of all the animal models of preeclampsia, the sFLT1 shows the greatest promise because, in addition to the hypertension and proteinuria, it is the only animal model with clearly shown glomerular endotheliosis.

These models are definitely of use in preeclampsia research but because this disease only occurs spontaneously in primates, ${ }^{1}$ the definitive studies on preeclampsia will, of necessity, be clinical.

\section{References}

1. Phippard, AF.; Horvath, JS. Animal models of preeclampsia. In: Rubin, PC., editor. Handbook of Hypertension (vol 10). Hypertension in Pregnancy. Amsterdam: Elsevier; 1988. p. 168-185.

2. National High Blood Pressure Education Program Working Group. Report on High Blood Pressure in Pregnancy. Consensus report. Am J Obstet Gynecol 1990;163:1689-1712.

3. Taylor RN. Review: Immunobiology of preeclampsia. Am J Reprod Immunol 1997;37:79-86. [PubMed: 9138457]

4. Roberts JM, Taylor RN, Goldfien A. Clinical and biochemical evidence of endothelial cell dysfunction in the pregnancy syndrome preeclampsia. Am J Hypertens 1991;4:700-708. [PubMed: 1930853]

5. Takeda T. Experimental study on the blood pressure of pregnant hypertensive rats. Jpn Circ J 1964;28:49-54. [PubMed: 14107894]

6. Deng A, Baylis C. Glomerular hemodynamic responses to pregnancy in the rat with severe reduction of renal mass. Kidney Int 1995;48:39-44. [PubMed: 7564089]

7. Baylis C. Glomerular filtration and volume regulation in gravid animal models. Baillieres Clin Obstet Gynaecol 1994;8:235-264. [PubMed: 7924007]

8. Baylis C. Physiology of GFR in normal and abnormal pregnancy. Semin Nephrol 1998;18:208-230. [PubMed: 9541274]

9. Baylis C, Deng A, Couser WG. Glomerular hemodynamic effects of late pregnancy in rats with membranous glomerulonephritis produced by the anti Fx1A antibody. J Am Soc Nephrol 1995;6:1197-1201. [PubMed: 8589286]

10. Longo LD. Maternal blood volume and cardiac output during pregnancy: A hypothesis of endocrinologic control. Am J Physiol 1983;245:R720-R729. [PubMed: 6356942]

11. Brosens I. A study of the spiral arteries of the decidua basalis in normotensive and hypertensive pregnancies. J Obstet Gynecol Br Common 1964;71:222-230.

12. Lunell NO, Lewander R, Mamoun I, et al. Uteroplacental blood flow in pregnancy induced hypertension. Scand J Clin Lab Invest 1984;44(suppl):28-39.

13. Ogden E, Hildebrand GJ, Page EW. Rise of blood pressure during ischemia of gravid uterus. Proc Soc Exp Biol Med 1940;43:49-51.

14. Young J. The etiology of eclampsia and albuminuria and their relation to accidental hemorrhage. J Obstet Gynecol Br Empire 1914;26:1-5.

15. Woods LL, Brooks VL. Role of the renin-angiotensin system in hypertension during reduced uteroplacental perfusion pressure. Am J Physiol 1989;257:R204-R209. [PubMed: 2665522] 
16. Woods LL. Importance of prostaglandins in hypertension during reduced uteroplacental perfusion pressure. Am J Physiol 1989;257:R1558-R1561. [PubMed: 2604012]

17. Losonczy GY, Mucha I, Dipirro J, et al. The effect of pregnancy on the response to the TXA2/PGH2 analogue U-46,619 in rabbits. Am J Physiol 1993;265:R772-R780. [PubMed: 8238446]

18. Losonczy GY, Mucha I, Venuto R. Pregnancy enhances the pressor response to thromboxane analogues in rabbits. Am J Physiol 1995;269:R720-R725. [PubMed: 7573575]

19. Losonczy GY, Brown G, Mucha I, et al. Gestational resistance to the pulmonary vasoconstrictor effect of the TXA2 mimetic U-46619: Possible mechanism. Am J Physiol 1997;272:R1743-R1739.

20. Kriston T, Venuto R, Baylis C, et al. The hemodynamic and renal effects of U-46619, a TXA2/PGH2 analog, in pregnant rats. Am J Physiol 1999;276:R831-R837. [PubMed: 10070145]

21. Abitbol MM. A simplified technique to produce toxemia in the pregnant dog. Am J Obstet Gynecol 1981;139:526-534. [PubMed: 7468720]

22. Abitbol MM, Gallo GR, Pirani CL, et al. Production of experimental toxemia in the pregnant rabbit. Am J Obstet Gynecol 1976;124:460-470. [PubMed: 1258901]

23. Losonczy GY, Todd H, Palmer DC, et al. Prostaglandins, norepinephrine, angiotensin II and blood pressure changes induced by uteroplacental ischemia in rabbits. Clin Exp Hypertens Pregnancy 19861987;B5:271-294.

24. Losonczy GY, Brown G, Venuto RC. Increased peripheral resistance during reduced uterine perfusion pressure hypertension in pregnant rabbits. Am J Med Sci 1992;303:233-240. [PubMed: 1562040]

25. Eder DJ, MacDonald MT. A role for brain angiotensin II in experimental pregnancy-induced hypertension in laboratory rats. Clin Exp Hypertens Preg 1987-1988;B6:431-451.

26. Alexander BT, Kassab SE, Miller MT, et al. Reduced uterine perfusion pressure during pregnancy in the rat is associated with increases in arterial pressure and changes in renal nitric oxide. Hypertension 2001;37:1191-1195. [PubMed: 11304523]

27. Crews JK, Herrington JN, Granger JP, et al. Decreased endothelium-dependent vascular relaxation during reduction of uterine perfusion pressure in pregnant rats. Hypertension 2000;35:71-76.

28. Alexander BT, Rinewalt AN, Cockrell KL, et al. Endothelin-A receptor blockade attenuates the hypertension in response to chronic reductions in uterine perfusion pressure. Hypertension 2001;37:485-489. [PubMed: 11230323]

29. Linas MT, Alexander BT, Abram SR, et al. Enhanced production of thromboxane A2 in response to chronic reductions in uterine perfusion pressure in pregnant rats. FASEB J 2001;15:A788.(abstr)

30. Clark KE, Durnwald M, Austin JE. A model for studying chronic reduction in uterine blood flow in pregnant sheep. Am J Physiol 1982;242:H297-H301. [PubMed: 7065164]

31. Leffler CW, Hessler JR, Green RS. Effects of sodium chloride on pregnant sheep with reduced uteroplacental perfusion pressure. Hypertension 1986;8:62-65. [PubMed: 3943887]

32. Abitbol MM, Ober WB, Gallo GR, et al. Experimental toxemia of pregnancy in the monkey, with a preliminary report on renin and aldosterone. Am J Pathol 1977;86:573-590. [PubMed: 402816]

33. Combs CA, Katz MA, Kitzmiller JL. Experimental preeclampsia produced by chronic constriction of the lower aorta: validation with longitudinal blood pressure measurements in conscious rhesus monkeys. Am J Obstet Gynecol 1993;169:215-223. [PubMed: 8333460]

34. Zhou Y, Chiu K, Brescia RJ. Increased depth of trophoblast invasion after constriction of the lower aorta in rhesus monkeys. Am J Obstet Gynecol 1993;169:224-229. [PubMed: 8333462]

35. Zhou Y, Damsky CH, Fisher SJ. Preeclampsia is associated with failure of human cytotrophoblasts to mimic a vascular adhesion phenotype. J Clin Invest 1997;99:2152-2164. [PubMed: 9151787]

36. Cavanagh D, Rao PS, Knuppel RA, et al. Pregnancy-induced hypertension: Development of a model in the pregnant primate (Papio anubis). Am J Obstet Gynecol 1985;151:987-999. [PubMed: 3885739]

37. Hutten JWM, Kuijpers JC, van Velzen D, et al. Pathogenesis of pregnancy-induced hypertensive disorders. A review of experimental animal models. Clin Exp Hypertens Pregnancy 1991;10:287306.

38. Hodari AA. Chronic uterine ischemia and reversible experimental "toxemia of pregnancy". Am J Obstet Gynecol 1967;97:597-607. [PubMed: 6018981] 
39. Bregulla K, Hennig F. Untersuchungen zum problem des schwangerschafts-hochdrucks als folge einer uteroplacentaren Ischaemie. Archive Gynacology 1977;222:345-350.

40. Misenhimer HR, Ramsey EM, Martin CB, et al. Chronically impaired uterine artery blood flow. Obstet Gynecol 1970;36:415-420. [PubMed: 4988963]

41. Cavanagh D, Rao PS, Tung KSK, et al. Eclamptogenic toxemia: The development of an experimental model in the subhuman primate. Am J Obstet Gynecol 1974;120:183-196. [PubMed: 4606463]

42. Cananagh D, Rao PS, Tsai CC, et al. Experimental toxemia in the pregnant primate. Am J Obstet Gynecol 1977;128:75-84. [PubMed: 403766]

43. Zatz R, Baylis C. Chronic nitric oxide inhibition model six years on. Hypertension 1998;32:958-964. [PubMed: 9856957]

44. Shesely EG, Gilbert C, Granderson G, et al. Nitric oxide synthase gene knockout mice do not become hypertensive during pregnancy. Am J Obstet Gynecol 2001;185:1198-1203. [PubMed: 11717657]

45. Hefler LA, Tempfer CB, Moreno RM, et al. Endothelial-derived nitric oxide and angiotensinogen: Blood pressure and metabolism during mouse pregnancy. Am J Physiol 2001;280:R174-R182.

46. Baylis C, Engels K. Adverse interactions between pregnancy and a new model of systemic hypertension produced by chronic blockade of endothelial derived relaxing factor (EDRF) in the rat. Clin Exp Hypertens 1992;11:117-129.

47. Yallampalli C, Garfield RE. Inhibition of nitric oxide synthesis in rats during pregnancy produces signs similar to those of preeclampsia. Am J Obstet Gynecol 1993;169:1316-1320. [PubMed: 8238200]

48. Molnar M, Suto T, Toth T. Prolonged blockade of nitric oxide synthesis in gravid rats produces sustained hypertension, proteinuria, thrombocytopenia, and intrauterine growth retardation. Am J Obstet Gynecol 1994;170:1458-1466. [PubMed: 7909994]

49. Salas SP, Altermatt F, Campos M. Effects of long term nitric oxide synthesis inhibition on plasma volume expansion and fetal growth in the pregnant rat. Hypertension 1995;26:1019-1023. [PubMed: 7498960]

50. Deng A, Engels K, Baylis C. Increased nitric oxide production plays a critical role in the maternal blood pressure and glomerular hemodynamic adaptations to pregnancy in the rat. Kidney Int 1996;50:1132-1138. [PubMed: 8887270]

51. Helmbrecht GD, Farhat MY, Lochbaum L, et al. L-arginine reverses the adverse pregnancy changes induced by nitric oxide synthesis inhibition in the rat. Am J Obstet Gynecol 1996;175:800-805. [PubMed: 8885725]

52. Cadnapaphornchai MA, Ohara M, Morris KG Jr, et al. Chronic NOS inhibition reverses systemic vasodilation and glomerular hyperfiltration in pregnancy. Am J Physiol 2001;280:F592-F598.

53. Diket AL, Pierce MR, Munshi UK, et al. Nitric oxide inhibition causes intrauterine growth retardation and hind-limb disruptions in rats. Am J Obstet Gynecol 1994;171:1243-1250. [PubMed: 7977528]

54. Greenberg SS, Lancaster JR, Xie J, et al. Effects of NO synthase inhibitors, arginine deficient diet, and amiloride in pregnant rats. Am J Physiol 1997;273:R1031-R1045. [PubMed: 9321883]

55. Baylis C, Beinder E, Suto T, et al. Recent insights into the roles of nitric oxide and renin-angiotensin in the pathophysiology of preeclampsia pregnancy. Semin Nephrol 1998;18:208-230. [PubMed: 9541274]

56. Danielson LA, Kercher LJ, Conrad KP. Impact of gender and endothelin on renal vasodilation and hyperfiltration induced by relaxin in conscious rats. Am J Physiol 2000;279:R1298-R1304.

57. Novak J, Danielson LA, Kerchner LJ, et al. Relaxin is essential for renal vasodilation during pregnancy in conscious rats. J Clin Invest 2001;107:1469-1475. [PubMed: 11390429]

58. Danielson LA, Conrad KP. Prostaglandins maintain renal vasodilation and hyperfiltration during chronic nitric oxide synthase blockade in conscious, pregnant rats. Circ Res 1996;79:1161-1166. [PubMed: 8943954]

59. Baylis C. Cyclooxygenase products do not contribute to the gestational renal vasodilation in the nitric oxide synthase inhibited pregnant rat. Hypertension in Pregnancy 2002;21:109-114. [PubMed: 12175438]

60. O’Donnell MP, Michels L, Kasiske B, et al. Adriamycin induced chronic proteinuria: A structural and functional study. J Lab Clin Med 1985;106:62-67. [PubMed: 4009023] 
61. Podjarny E, Rathaus M, Bernheim JL, et al. Captopril, but not diltiazem, favorably affects the course of early chronic renal disease in rats. Nephron 1990;55:196-202. [PubMed: 2256977]

62. Fogo A, Yoshida Y, Glick AD, et al. Serial micropuncture analysis of glomerular function in two rat models of glomerular sclerosis. J Clin Invest 1988;82:322-330. [PubMed: 3392211]

63. Podjarny E, Bernheim J, Rathaus M, et al. Adriamycin nephropathy: A model to study effects of pregnancy on renal disease in rats. Am J Physiol 1992;263:F711-F715. [PubMed: 1415742]

64. Fitzgerald DJ, Entman SS, Mullay K, et al. Thromboxane A2 synthesis in pregnancy induced hypertension. Lancet 1990;335:751-754. [PubMed: 1969511]

65. Rathaus M, Podjarny E, Pomeranz A, et al. Adriamycin related hypertension in pregnant rats: Response to a thromboxane receptor antagonist. Clin Sci 1995;88:623-627. [PubMed: 7634744]

66. Bernheim J, Podjarny E, Pomeranz A, et al. Pregnancy induced hypertension in rats with early adriamycin nephropathy. Nephrol Dial Transplant 1994;3(suppl):13-16. [PubMed: 8072719]

67. Rathaus M, Podjarny E, Benchetrit S, et al. Nitric oxide and vascular reactivity in pregnant rats with adriamycin nephropathy. Clin Sci 1997;93:227-234. [PubMed: 9337637]

68. Podjarny E, Haskia A, Pomeranz A, et al. Effect of diltiazem and methyldopa on the pregnancy related complication in rats with adriamycin nephrosis. Relationship to glomerular prostanoid synthesis. Nephrol Dial Transplant 1995;10:1598-1602. [PubMed: 8559476]

69. Podjarny E, Benchetrit S, Rathaus M, et al. Pregnancy induced hypertension in rats with adriamycin nephropathy is associated with an insufficient synthesis of nitric-oxide. Hypertension 1997;4:986989. [PubMed: 9095088]

70. Podjarny E, Pomeranz A, Rathaus M, et al. Effect of L-arginine treatment in pregnant rats with adriamycin nephropathy. Clin Exp Hypertens Pregnancy 1993;12:517-524.

71. Duquaine D, Hirsch GA, Chakrabarti A, et al. Rapid-onset endothelial dysfunction with adriamycin: Evidence for a dysfunctional nitric oxide synthase. Vasc Med 2003;8:101-107. [PubMed: 14518612]

72. Vasquez VJ, Martasek P, Hogg N, et al. Endothelial nitric oxide synthase-dependent superoxide generation from adriamycin. Biochemistry 1997;36:11293-11297. [PubMed: 9333325]

73. Pomeranz M, Podjarny E, Bernheim J, et al. Effect of recurrent pregnancies in the evolution of adriamycin nephropathy. Nephrol Dial Transplant 1995;10:2049-2054. [PubMed: 8643166]

74. Leaker B, Becker GJ, El-Khatib M, et al. Repeated pregnancy does not accelerate glomerulosclerosis in rats with subtotal renal ablation. Clin Exp Hypertens Pregnancy 1992;11:1-23.

75. Seely EW, Solomon CG. Insulin resistance and its potential role in pregnancy-induced hypertension. J Clin Endocrinol Metab 2003;88:2393-2398. [PubMed: 12788833]

76. Fuh TM, Yin CH, Pei D, et al. Resistance to insulin-mediated glucose uptake and hyperinsulinemia in women who had preeclampsia during pregnancy. Am J Hypertens 1995;8:768-771. [PubMed: 7546505]

77. Caruso A, Ferrazzani S, De Carolis S, et al. Gestational hypertension but not preeclampsia is associated with insulin resistance syndrome characteristics. Hum Reprod 1999;14:219-223. [PubMed: 10374124]

78. Sibai BM, el-Nazer A, Gonzalez-Ruiz A. Severe preeclampsia-eclampsia in young primigravid women: Subsequent pregnancy outcome and remote prognosis. Am J Obstet Gynecol 1986;155:1011-106. [PubMed: 3777042]

79. Smith GCS, Pell JP, Walsh D. Pregnancy complications and maternal risk of ischaemic heart disease: A retrospective cohort study of 129,290 births. Lancet 2001;357:2002-2006. [PubMed: 11438131]

80. Sermer M, Naylor CD, Gare DJ, et al. Impact of increasing carbohydrate intolerance on maternalfetal outcomes in 3637 women without gestational diabetes: The Toronto Trihospital Gestational Project. Am J Obstet Gynecol 1995;173:146-156. [PubMed: 7631672]

81. Joffe GM, Esterlitz JR, Levine RJ, et al. The relationship between abnormal glucose tolerance and hypertensive disorders of pregnancy in healthy nulliparous women: Calcium for Preeclampsia Prevention (CPEP) study group. Am J Obstet Gynecol 1998;179:1032-1037. [PubMed: 9790393]

82. Solomon CG, Graves SW, Greene MF, et al. Glucose intolerance as a predictor of hypertension in pregnancy. Hypertension 1994;23:717-721. [PubMed: 8206568]

83. Innes KE, Wimsatt JH, McDuffie R. Relative glucose tolerance and subsequent development of hypertension in pregnancy. Obstet Gynecol 2001;97:905-910. [PubMed: 11384694] 
84. Podjarny E, Bernheim J, Katz B, et al. Chronic exogenous hyperinsulinemia in pregnancy: A rat model for pregnancy induced hypertension. J Am Soc Nephrol 1998;9:9-13. [PubMed: 9440081]

85. Podjarny E, Bursztyn N, Rashed G, et al. Chronic exogenous hyperinsulinaemia-induced hypertension in pregnant rats: Effect of chronic treatment with L-arginine. Clin Sci 2001;100:667-671. [PubMed: 11352784]

86. Burztyn M, Podjarny E, Dahan R, et al. Insulin-induced hypertension, L-arginine, and endothelial nitric oxide synthase in pregnant rats. Hypertens Pregnancy 2003;22:267-274. [PubMed: 14572363]

87. Olatunji-Bello II, Nwachukwu D, Adegunloye BJ. Blood pressure and heart rate changes during pregnancy in fructose-fed Sprague-Dawley rats. Afr J Med Med Sci 2001;30:187-190. [PubMed: 14510126]

88. Maynard SE, Min JY, Merchan J, et al. Excess placental soluble fms-like tyrosine kinase 1 (sFlt1) may contribute to endothelial dysfunction, hypertension, and proteinuria in preeclampsia. J Clin Invest 2003;111:649-658. [PubMed: 12618519]

89. Levine RJ, Maynard SE, Qian C, et al. Circulating angiogenic factors and the risk of preeclampsia. N Engl J Med 2004;350:672-683. [PubMed: 14764923]

90. Thadhani R, Ecker JL, Mutter WP, et al. Insulin resistance and alterations in angiogenesis. Additive insults that may lead to preeclampsia. Hypertension 2004;43:988-992. [PubMed: 15023932]

91. Eremina V, Sood M, Haigh J, et al. Glomerular-specific alterations of VEGF-A expression lead to distinct congenital and acquired renal diseases. J Clin Invest 2003;111:707-716. [PubMed: 12618525]

92. Wergeland E, Strand K. Work pace control and pregnancy health in a population-based sample of employed women in Norway. Scand J Work Environ Health 1998;24:206-212. [PubMed: 9710373]

93. Pagel MD, Smilkstein G, Regen H, et al. Psychosocial influences on newborn outcome: A controlled prospective study. Soc Sci Med 1990;30:597-604. [PubMed: 2309138]

94. Schobel HP, Fisher T, Heuszer K, et al. Preeclampsia-a state of sympathetic hyperactivity. N Engl J Med 1996;335:1480-1485. [PubMed: 8890098]

95. Greenwood JP, Scott EM, Stoker JB, et al. Sympathetic neural mechanisms in normal and hypertensive pregnancy in humans. Circulation 2001;104:2200-2204. [PubMed: 11684631]

96. Takiuti NH, Kahhale S, Zugaib M. Stress in pregnancy: A new Wistar rat model for human preeclampsia. Am J Obstet Gynecol 2002;186:544-550. [PubMed: 11904621]

97. Kananyama N, She L, Maheara K, et al. HELLP syndrome-like biochemical parameters obtained with stimulation of celiac ganglion in rats. J Hypertens 1996;14:453-459. [PubMed: 8761894]

98. Kanayama N, Tsujimura R, She L, et al. Cold-induced stress stimulates the sympathetic nervous system, causing hypertension and proteinuria in rats. J Hypertens 1997;15:383-389. [PubMed: 9211173]

99. Wallukat G, Neichel D, Nissen E, et al. Agonistic autoantibodies directed against the angiotensin II AT1 receptor in patients with preeclampsia. Can J Physiol Pharmacol 2003;81:79-83. [PubMed: 12710518]

100. Takimoto E, Ishida J, Sugiyama F, et al. Hypertension induced in pregnant mice by placental renin and maternal angiotensinogen. Science 1996;274:995-998. [PubMed: 8875944]

101. Bohlender J, Ganten D, Luft FC. Rats transgenic for human renin and human angiotensinogen as a model for gestational hypertension. J Am Soc Nephrol 2000;11:2056-2061. [PubMed: 11053481]

102. Redman CW, Sargent IL. Pre-eclampsia, the placenta and the maternal systemic inflammatory response-a review. Placenta 2003;24A(suppl):S21-S27. [PubMed: 12842410]

103. Conrad KP, Benyo DF. Placental cytokines and the pathogenesis of preeclampsia. Am J Reprod Immunol 1997;37:240-249. [PubMed: 9127646]

104. Many A, Hubel CA, Fisher SJ, et al. Invasive cytotrophoblasts manifest evidence of oxidative stress in preeclampsia. Am J Pathol 2000;156:321-331. [PubMed: 10623681]

105. Myatt L, Rosenfield RB, Eis ALW, et al. Nitrotyrosine residues in placenta. Evidence of peroxynitrite formation and action. Hypertension 1996;28:488-493. [PubMed: 8794838]

106. Li H, Meininger CJ, Hawker JR, et al. Regulatory role of arginase I and II in nitric oxide, polyamine, and proline syntheses in endothelial cells. Am J Physiol 2001;280:E75-E82. 
107. Noris M, Todeschini M, Cassis P, et al. L-arginine depletion in preeclampsia orients nitric oxide synthase toward oxidant species. Hypertension 2004;43:614-622. [PubMed: 14744923]

108. Vizi ES, Szelenyi J, Selmeczy ZS, et al. Enhanced tumor necrosis factor-alpha-specific and decreased interleukin-10-specific immune responses to LPS during the third trimester of pregnancy in mice. J Endocrinol 2001;171:355-361. [PubMed: 11691656]

109. Faas MM, Schuiling GA, Baller JFW. A new animal model for human preeclampsia: Ultra-lowdose endotoxin infusion in pregnant rats. Am J Obstet Gynecol 1994;171:158-164. [PubMed: 8030692]

110. Raij L. Glomerular thrombosis in pregnancy: Role of the L-arginine-nitric oxide pathway. Kidney Int 1994;45:775-781. [PubMed: 8196278]

111. Hung TH, Charnock-Jones DS, Skepper JN, et al. Secretion of tumor necrosis factor-alpha from human placental tissues induced by hypoxia-reoxygenation causes endothelial cell activation in vitro: A potential mediator of the inflammatory response in preeclampsia. Am J Pathol 2004;164:1049-1061. [PubMed: 14982858]

112. Alexander BT, Cockrell KL, Massey MB, et al. Tumor necrosis factor-alpha-induced hypertension in pregnant rats results in decreased renal neuronal nitric oxide synthase expression. Am J Hypertens 2002;15:170-175. [PubMed: 11863253]

113. Giardina JB, Green GM, Cockrell KL, et al. TNF-alpha enhances contraction and inhibits endothelial NO-cGMP relaxation in systemic vessels of pregnant rats. Am J Physiol 2002;283:R130-R143.

114. Kirwan JP, Hauguel-De Mouzon S, Lepercq J, et al. TNF is a predictor of insulin resistance in human pregnancy. Diabetes 2002;151:2207-2213. [PubMed: 12086951]

115. McCarron DA, Morris C, Cole C. Dietary calcium and human hypertension. Science 1982;217:267269. [PubMed: 7089566]

116. Izumi A, Minakami H, Sato I. Calcium to creatinine ratio in spot urine samples in early pregnancy and its relation to the development of preeclampsia. Metabolism 1997;46:1107-1108. [PubMed: 9322789]

117. Belizan JM, Pineda O, Sainz E. Rise of blood pressure in calcium pregnant deprived rats. Am J Obstet Gynecol 1981;141:163-169. [PubMed: 7282791]

118. Prada JA, Tsang RC, Clark KE. Hypocalcemia and pregnancy-induced hypertension produced by low-calcium diet. Hypertension 1994;23:695-702. [PubMed: 8206565]

119. Sibai BM, Ewell M, Levine RJ. Risk factors associated with preeclampsia in healthy nulliparous women: The calcium for preeclampsia prevention (CPEP) study group. Am J Obstet Gynecol 1997;177:1003-1010. [PubMed: 9396883]

120. Podjarny E, Baylis C, Losonczy G. Animal models of Preeclampsia. Semin Perinatol 1999;23:213. [PubMed: 10102166] 


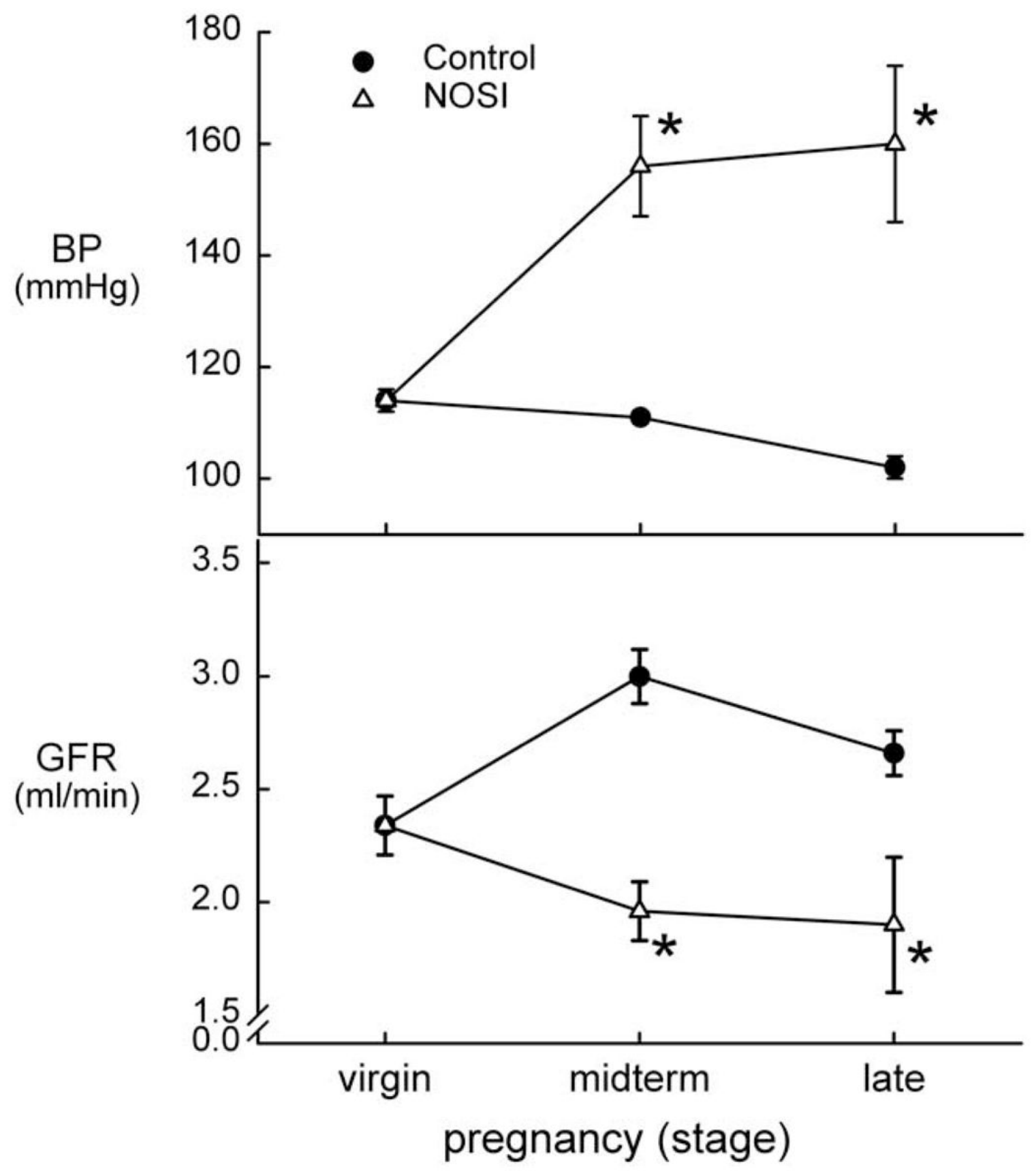

Figure 1.

Mean arterial BP and GFR in normal control rats $(\bullet)$ and in rats with chronic NOS inhibition $(\triangle)$, during pregnancy. *Significant difference versus the virgin value. Data from Baylis and Engels. ${ }^{46}$ Reproduced from Podjarny et al with permission. ${ }^{120}$ 


\section{a}

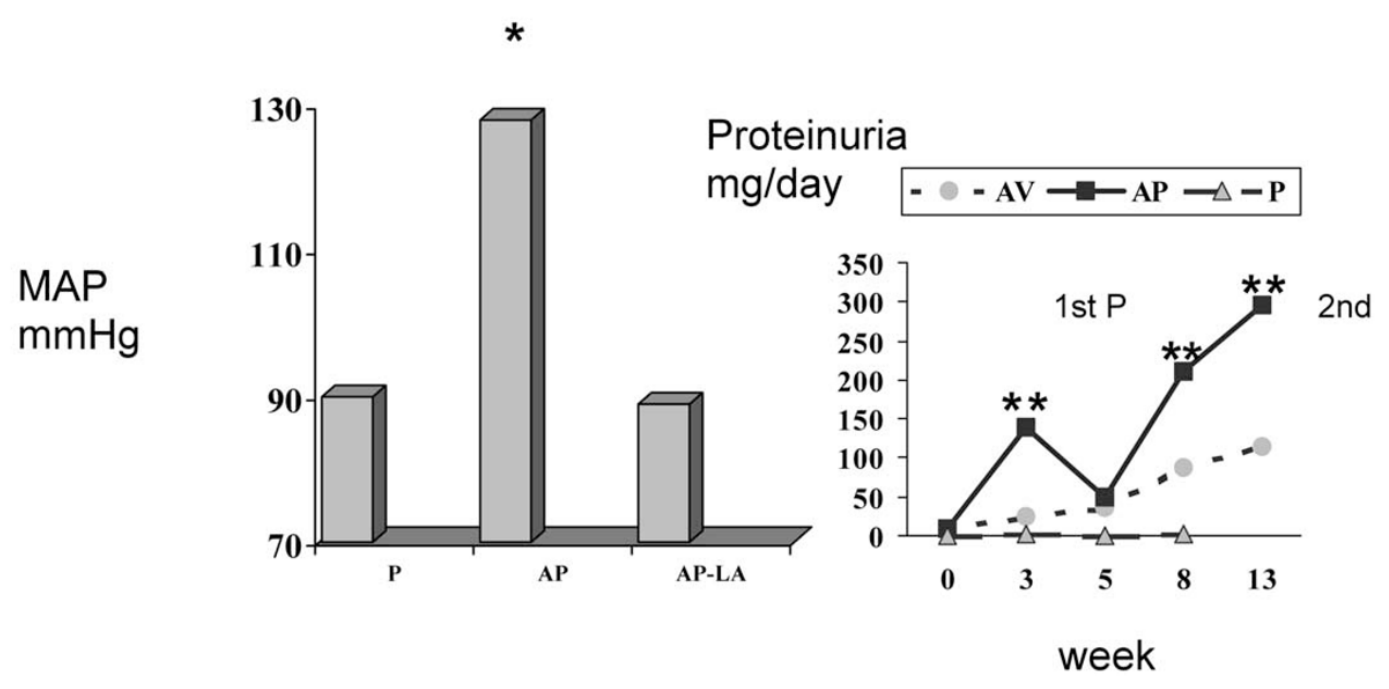

Figure 2.

(A) Mean arterial pressure (MAP) at the end of pregnancy. P, normal pregnant rats; AP, adriamycin pregnant rats; AP-LA, AP rats treated with L-arginine orally, $2 \mathrm{~g} / \mathrm{L}$ from midpregnancy. $* P<.001$ versus $\mathrm{P}$ and $\mathrm{P}-\mathrm{LA}$ values; $* * P<.01$ versus AP and AP-N values. (B) Twenty-four hour urine protein excretion $(\mathrm{UpV})$ through repetitive pregnancies $(\mathrm{p})$ in rats with adriamycin nephropathy. The time in weeks corresponds to the following events: $0=$ beginning of first $\mathrm{P} ; 3$ = end first $\mathrm{P} ; 5=$ beginning of 2 nd $\mathrm{P} ; 8=$ end of 2 nd $\mathrm{P} ; 13=5$ weeks after second delivery. AV, virgin rats with adriamycin nephropathy; AP, pregnant rats with adriamycin nephropathy; $\mathrm{P}$, normal pregnant rats. $* P<.001$ versus $\mathrm{P}$ and AV values. $\odot, A V$; $\mathbf{-}, \mathrm{AP} ; \boldsymbol{\Delta}, \mathrm{P}$. 


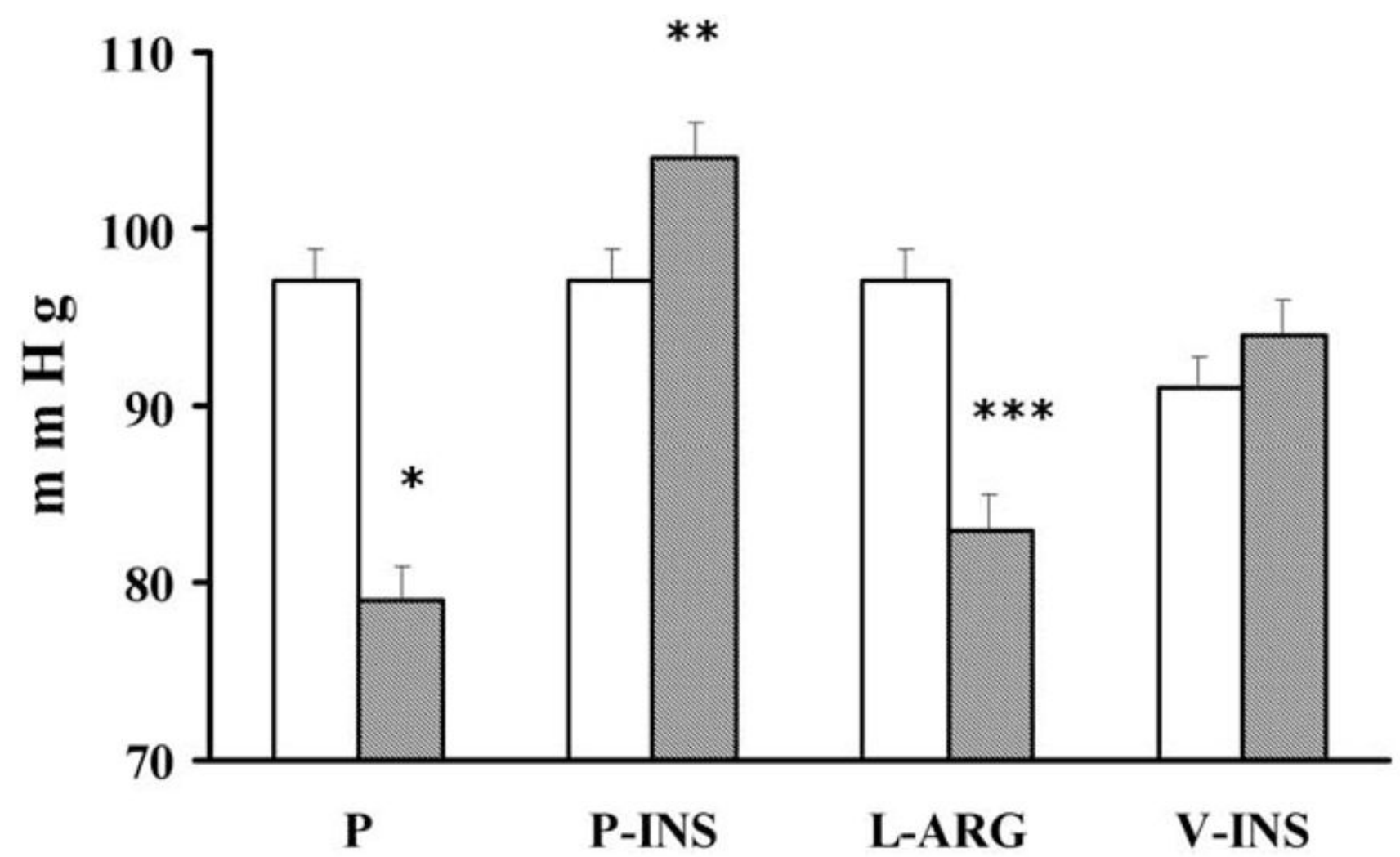

Figure 3.

The clear columns show values before pregnancy and the shaded columns show values at the end of pregnancy. P, normal pregnant rats; P-INS, hyperinsulinemic pregnant rats; L-ARG, hyperinsulinemic pregnant rats treated with L-arginine $2 \mathrm{~g} / \mathrm{L}$ from midpregnancy; V-INS, hyperinsulinemic virgin rats. ${ }^{*} P<.01$ versus $\mathrm{P}$ rats before pregnancy; $* * P<.01$ versus the same group before pregnancy and versus $P$ rats at the end of pregnancy; $* * * P<.01$ versus the same group before pregnancy and versus P-INS rats at the end of pregnancy. Reproduced with permission from Podjarny et al. ${ }^{85}$ 


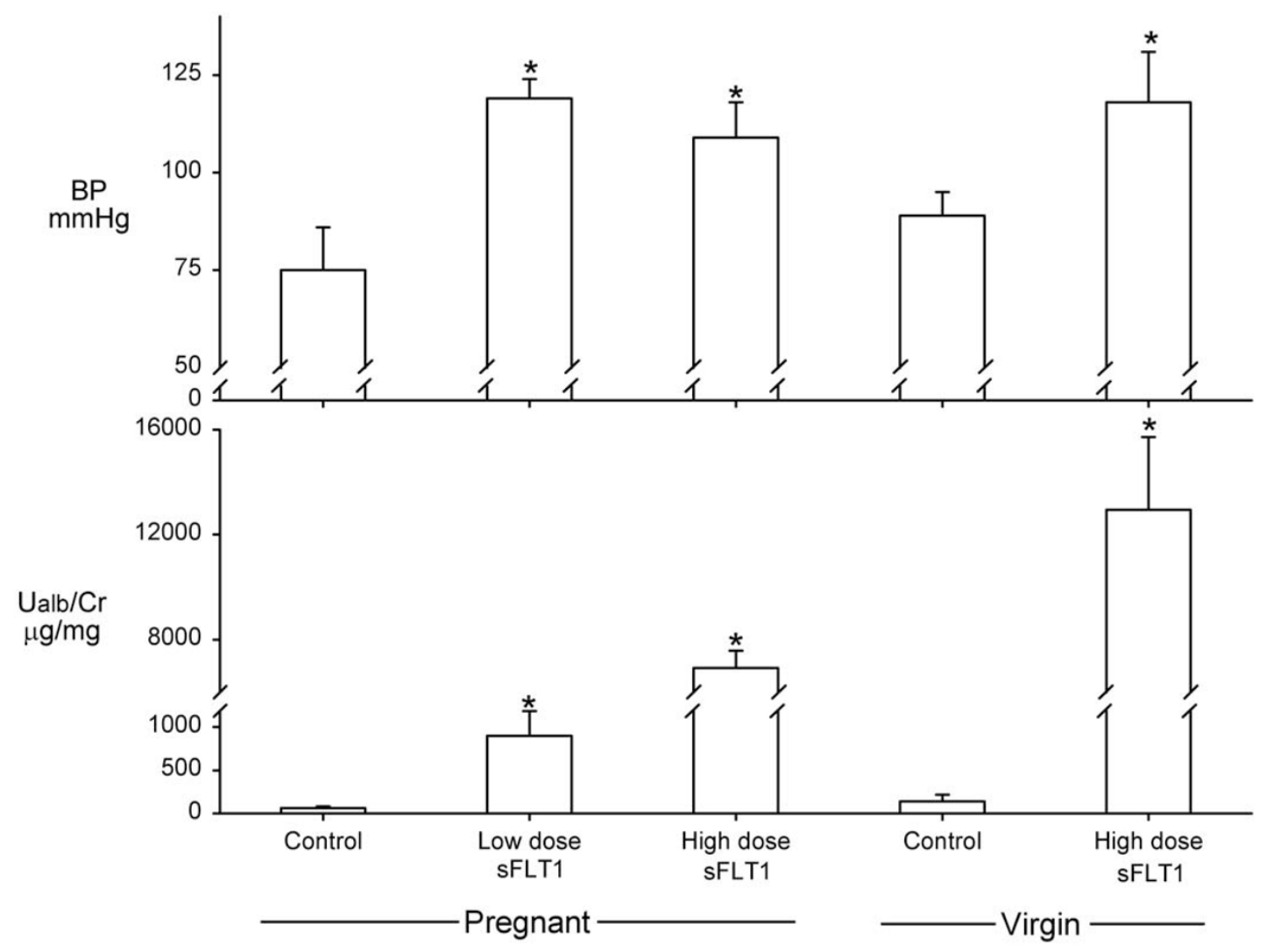

Figure 4.

Mean arterial BP and urinary albumin/creatinine ratio $(\mathrm{Ualb} / \mathrm{Cr})$ in late pregnant and virgin rats. Controls received adenovirus expressing mouse $\operatorname{IgG} 2 \alpha \mathrm{Fc}$; others received adenovirus expressing either low or high levels of the soluble form of the FLT1 VEGF receptor (sFLT1) that antagonizes the actions of VEGF and PIGF P < 0.01 vs control. Data from Maynard et al. 88 